\title{
Australian Livestock Export Industry Workers' Attitudes toward Animal Welfare
}

\author{
Renee S. Willis $^{1, * \mathbb{D}}$, Emma J. Dunston-Clarke ${ }^{1} \mathbb{D}$, Leah R. Keating ${ }^{1}$, Patricia A. Fleming ${ }^{2} \mathbb{D}$ and Teresa Collins ${ }^{1} \mathbb{D}$ \\ 1 Food Futures Institute, Murdoch University, Murdoch, WA 6150, Australia; \\ Emma.Dunston@murdoch.edu.au (E.J.D.-C.); leah_257@outlook.com (L.R.K.); \\ t.collins@murdoch.edu.au (T.C.) \\ 2 Harry Butler Institute, Murdoch University, Murdoch, WA 6150, Australia; t.fleming@murdoch.edu.au \\ * Correspondence: reneeswillis@gmail.com
}

Citation: Willis, R.S.; Dunston-Clarke, E.J.; Keating, L.R.; Fleming, P.A.; Collins, T. Australian Livestock Export Industry Workers' Attitudes toward Animal Welfare. Animals 2021, 11, 1411. https://doi.org/10.3390/ ani11051411

Academic Editor: Frank J.C.M Van Eerdenburg

Received: 7 April 2021

Accepted: 12 May 2021

Published: 14 May 2021

Publisher's Note: MDPI stays neutral with regard to jurisdictional claims in published maps and institutional affiliations.

Copyright: (c) 2021 by the authors. Licensee MDPI, Basel, Switzerland. This article is an open access article distributed under the terms and conditions of the Creative Commons Attribution (CC BY) license (https:// creativecommons.org/licenses/by/ $4.0 /)$.
Simple Summary: Societal concern for the welfare of animals in the Australian live export industry is substantial, with particular concern shown for animals after they have left Australian shores. The competency of stock handlers is recognized as one of the most important factors affecting the welfare of exported livestock. Therefore, a survey of 265 industry workers was undertaken to gauge their understanding of animal welfare, their attitudes toward welfare in their workplace, and to identify any differences according to their industry role. Surveys were disseminated in six languages to twenty different supply chain locations in Australia, Southeast Asia, and the Middle East. The majority of respondents showed a strong understanding and positive attitude toward animal welfare concepts. Participants generally felt that livestock welfare was important to them and that livestock should be treated with respect. Responses were analyzed according to participants' role in industry, finding that there was minimal variation in beliefs or attitudes between supply chain roles, and no specific group was found to differ from others consistently. The majority of participants identified ways they had positively impacted livestock welfare in the past and provided suggestions for additional improvements within industry. These findings may be useful for addressing the discordance between societal perceptions and those of industry workers.

Abstract: Understanding live export industry workers' attitudes and beliefs toward animal welfare can provide insight into their decision-making processes and likely behavior. Industry workers $(n=265)$ with various roles within the supply chain were surveyed from different global regions. Participants were divided into ten categories according to their industry roles and compared using ordinal regression. Respondents were highly likely to have a positive attitude toward animal welfare; the majority of workers enjoyed working with livestock (95.8\%) and agreed that livestock should be treated with respect $(97.7 \%)$. Workers demonstrated a strong understanding of animal welfare concepts, 168 respondents $(63.4 \%)$ provided examples of ways they had improved animal welfare in their workplace, and 164 workers (61.9\%) suggested ways that animal welfare could be improved further. Most workers (95.8\%) agreed that animal welfare was satisfactory in their workplace. Five out of the 24 multiple-choice responses differed significantly by the participant's industry role, but no particular group displayed consistently divergent beliefs or attitudes. Given the community concern regarding animals in the livestock export supply chain, it is imperative to understand the attitudes of industry personnel who are responsible for the daily management of the animals. This knowledge assists in the development of animal welfare policy and can inform strategies to manage public perception.

Keywords: stockperson; stock handler; husbandry; transportation; societal perceptions; farm animal welfare 


\section{Introduction}

The welfare of livestock exported by sea is of particular interest to the Australian public. The live export industry receives frequent attention in the media and from animal advocacy groups $[1,2]$. Significant concern has been generated by media attention highlighting incidents of poor handling and inhumane slaughter practices in countries receiving Australian livestock $[1,3,4]$. Human-animal interactions are recognized as a significant contributor to welfare outcomes during livestock transport and in production animal systems $[5,6]$. The interactions between livestock and their handlers can positively or negatively affect animal well-being [7]. In the livestock export industry, workers implement procedures and regulations regarding animal health and welfare and make critical decisions that directly impact livestock throughout the supply chain (e.g., daily monitoring of livestock, provision of resources and health care, reporting on health and welfare outcomes as stipulated under industry regulatory requirements). Previously, members of the general public, animal welfare advocates, and those working in the industry have ranked the attitude and competency of stockpersons as two of the top three most important industry welfare factors [8]. Livestock export involves transporting animals to multiple nations globally. Consequently, exported animals move between several supply chain facilities and are regularly handled and managed by workers from different cultural backgrounds with a range of stock handling expertise. Furthermore, human-animal interactions and management practices early in the export supply chain can exacerbate welfare outcomes as animals are exposed to intense handling and different management conditions when moving between facilities along their journey [9].

Animal handling practices have previously been identified as a crucial factor influencing animal welfare in the live export industry $[10,11]$. In 2011, the Export Supply Chain Assurance System (ESCAS) was introduced in response to poor handling and slaughter practices in many facilities receiving Australian livestock [11,12]. ESCAS aims to ensure that animal handling and slaughter practices for Australian livestock in importing countries meet the World Organization for Animal Health (OIE) recommendations. Despite the introduction of ESCAS, surveys of the public have identified ongoing concern for the handling of animals after leaving Australian shores $[8,13]$. The live export industry is aware that public perception and evolving community values regarding animal welfare need to be addressed $[3,14]$. Surveys of public attitudes toward the livestock export industry demonstrate that some community members believe industry workers do not have high regard for animal welfare [13]. This follows a broader trend, whereby the role of stock handlers in production animal systems is often undervalued [15]. Surveys have been undertaken to assess society's opinions on animal welfare in the livestock export industry [14,16,17]; however, studies to investigate industry workers' attitudes toward livestock welfare and how attitudes may differ between supply chain sectors are limited $[8,18]$. Despite the importance of their role(s), industry workers are often overlooked during decision making processes or regulatory reform. However, workers can be a constructive resource for identifying welfare issues and implementing possible solutions [15,19]. Stock handlers' attitudes, beliefs, and comprehension of animal welfare are integral drivers for determining the likely nature of their interactions with livestock $[15,20]$.

A person's behavior is influenced by their own beliefs and attitudes, by the values of those around them, and their perceived ability to act in a particular manner [21,22]. It is well established that these principles apply to stock handlers [5,21,23]; therefore, analyzing these elements can indicate the expected nature of stock handlers' interactions with livestock, and their impact on animal welfare. Previous studies have also identified factors that influence the attitudes of stock handlers toward animal welfare, and these may apply to live export workers. Southeast and East Asian stakeholders identified demographic factors such as gender, religion, and previous experience with farm animals as influential [24-26]. In addition, level of training $[5,26,27]$, working conditions such as salary, respect, and job satisfaction, can impact worker attitudes [15]. Therefore, understanding worker attitudes 
and beliefs at different supply chain sectors may help identify factors that can be modified or improved.

This study surveyed participants who worked at various points in the Australian livestock export supply chain aiming to: (1) examine workers' attitudes and understanding of animal welfare; (2) determine their perception of animal welfare in their workplace; and (3) ascertain whether workers' attitudes were influenced by their role in the supply chain.

\section{Materials and Methods}

\subsection{Participant Recruitment and Survey Distribution}

This study was approved by the Murdoch University Human Research Ethics Committee (2018/022). Researchers used an information sheet and verbal communication to confirm the aims, informed consent, voluntary nature, and individual confidentiality of the collected information. All survey questions were optional.

Participants were invited and eligible for recruitment if they were employees in the Australian livestock export industry supply chain, either in Australia and overseas. The survey design was based on other published surveys testing livestock handlers' attitudes to animals $[23,25,28,29]$ and incorporating the Theory of Planned Behavior $[22,30]$. Questions were adapted to suit the livestock export context and divided into three parts:

- Part 1: Ten demographic questions (e.g., age, nationality, role in industry) (Figure 1).

- Part 2: Eighteen questions on attitudes and personal beliefs toward animal welfare and animal sentience [28]; livestock handling and acceptable workplace practices [23]; and euthanasia of livestock [25] (Table 1).

- Part 3: Six questions regarding the respondent's opinions on their current working environment and the welfare of livestock within it [29], as well as their perception of co-workers (Table 1). In addition, two short answer questions were asked on how the welfare of exported animals could be improved and ways that the participant had improved animal welfare in the past (if any).

Survey responses were measured on a five-point Likert scale from 'strongly agree' to 'strongly disagree' for questions regarding opinions on welfare, and 'all of the time' to and 'never' for questions on handling livestock. Questions in Parts 2 and 3 were presented to reduce bias by randomly alternating between affirmative and negative answers and between questions on both cattle and sheep; this enabled identification of whether participants had interpreted the questions consistently. Respondents were also asked to provide examples of their experiences and welfare considerations in a free text format. Providing meaningful short answer responses required an understanding of animal welfare issues and reduced the participant's ability to choose proposed answers based on what was perceived as socially acceptable [26].

The survey was translated to Arabic, Bangla, Vietnamese, Filipino, and Bahasa Indonesian languages, with respondents able to select their language to ensure the accuracy of understanding. Surveys included a definition for 'euthanasia' and 'welfare' to facilitate respondents' interpretation of questions.

Flyers advertising the survey were distributed to workplaces such as feedlots in Australia and overseas, at Fremantle Port during the loading of livestock carrier vessels, and on-board during voyages. Convenience sampling was also employed, with data collection dependent on scheduled livestock consignments from Australia during the data collection period (August 2018 to April 2019). Surveys were distributed by email link from the chief investigator to export company managers, and in paper form by four Australian Government Accredited Veterinarians, one Australian Accredited Stockperson and two industry researchers. To maintain confidentiality and encourage participants to respond honestly, surveys were completed anonymously, with hard copy surveys enabling workers to answer at their own pace and return surveys in a closed folder or envelope. 


\section{a) Survey Language}

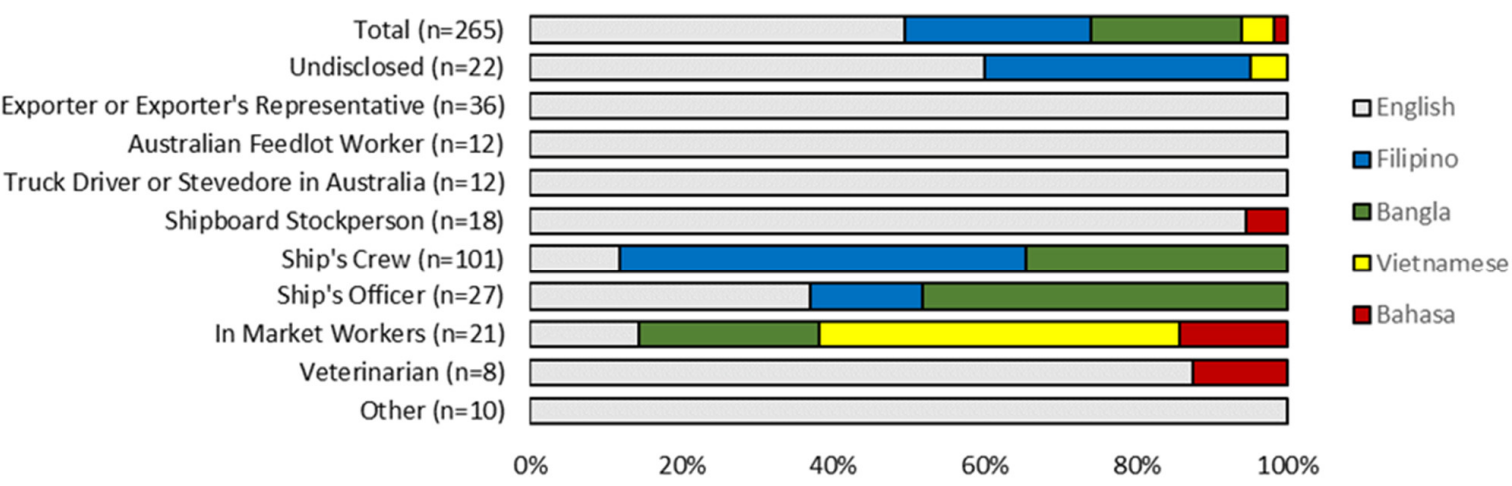

\section{b) Nationality (by country or region)}

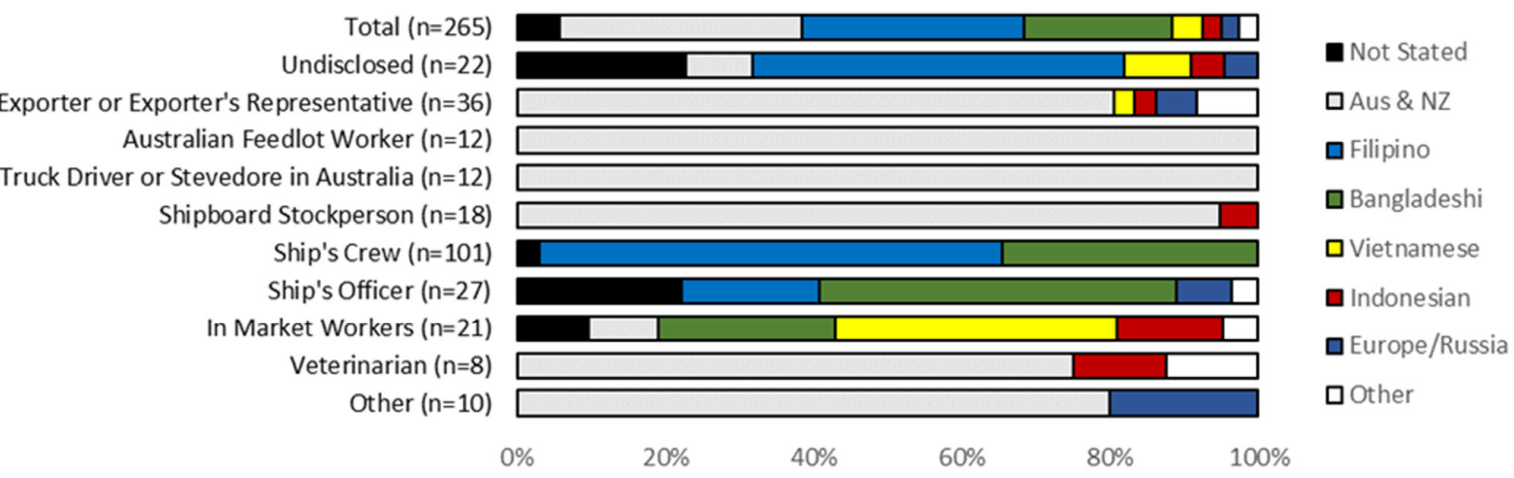

c) Religion

Total $(n=265)$ Undisclosed $(n=22)$

Exporter or Exporter's Representative $(n=36)$ Australian Feedlot Worker $(n=12)$ Truck Driver or Stevedore in Australia ( $n=12$ ) Shipboard Stockperson $(n=18)$ Ship's Crew $(n=101)$ Ship's Officer $(n=27)$ In Market Workers ( $\mathrm{n}=21$ ) Veterinarian $(n=8)$ Other $(n=10)$

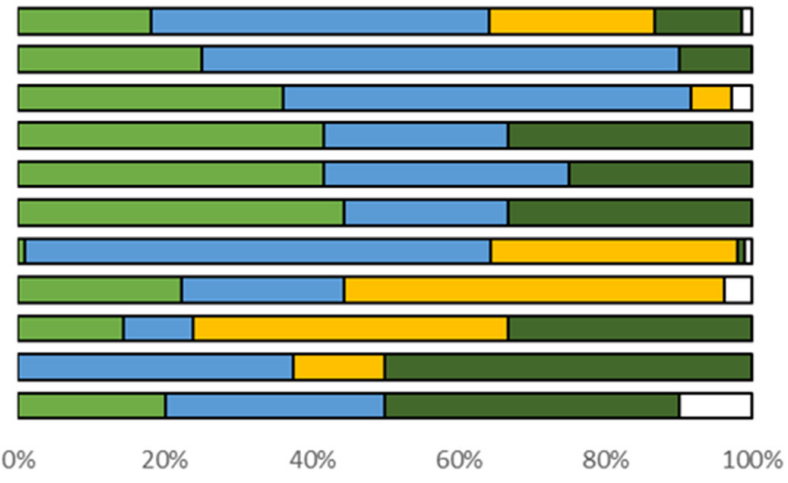

\section{d) Gender}

Total $(n=265)$

Undisclosed $(n=22)$

Exporter or Exporter's Representative ( $n=36$ ) Australian Feedlot Worker $(n=12)$

Truck Driver or Stevedore in Australia ( $n=12$ ) Shipboard Stockperson $(n=18)$ Ship's Crew ( $n=101)$ Ship's Officer ( $n=27$ In Market Workers $(n=21)$ Veterinarian $(n=8)$ Other $(n=10)$

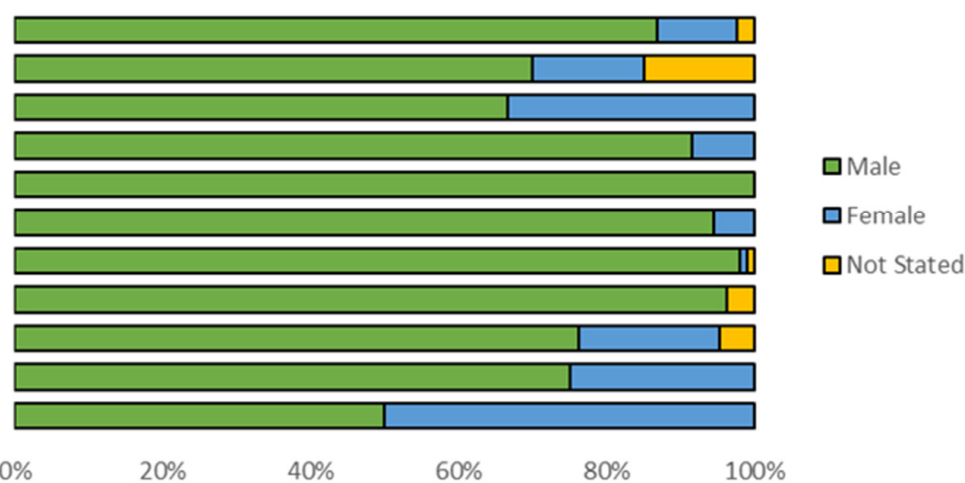

Figure 1. Cont. $\square$ Male
$\square$ Female

$\square$ Not Stated $\square$ Not Stated

Christian

口Islamic

口Atheist

口Other Religion 
e) Age

Total $(n=265)$

Undisclosed $(n=22)$

Exporter or Exporter's Representative ( $n=36$ )

Australian Feedlot Worker $(n=12)$

Truck Driver or Stevedore in Australia $(n=12)$

Shipboard Stockperson $(n=18)$

Ship's Crew $(n=101)$

Ship's Officer $(n=27)$

In Market Workers ( $n=21)$

Veterinarian $(n=8)$

Other $(n=10)$

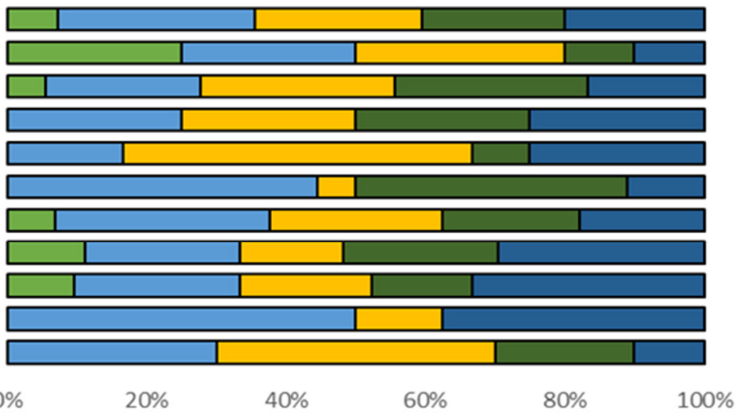

$\square$ Not Stated

$\square<30$

ㅁ30-39

ㅁ 40-49

$\square>50$

$\begin{array}{llllll}0 \% & 20 \% & 40 \% & 60 \% & 80 \% & 100 \%\end{array}$

\section{f) Education}

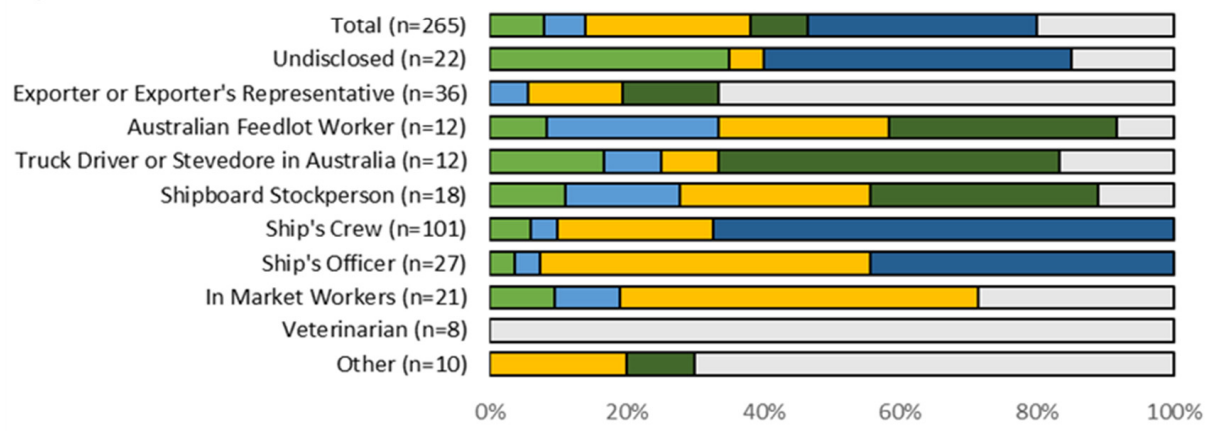

$\square$ Not Stated

口Attended School

口Completed high school

Trade/Certificate

Tertiary Education (Marine Academy)

口Tertiary Education

(Other)

g) Formal training in working with livestock

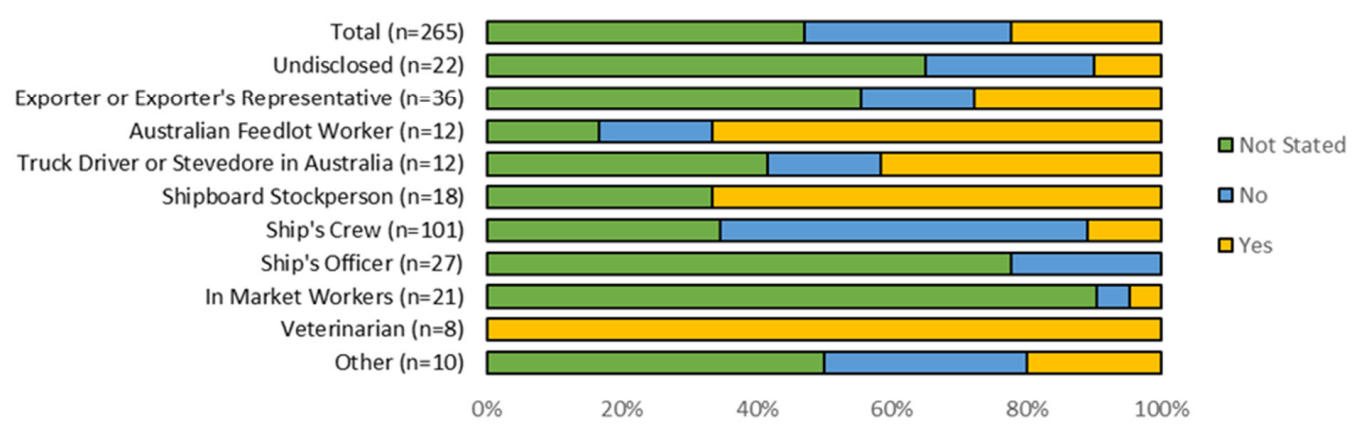

h) Have you ever owned or worked with farm animals that are not from Australia?

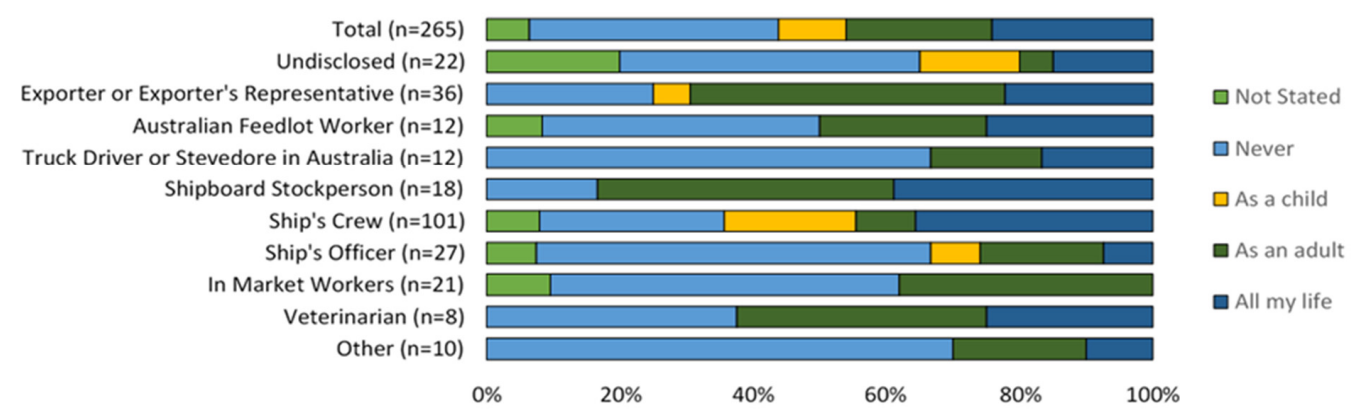

Figure 1. (a-h) Demographics by role in industry. 


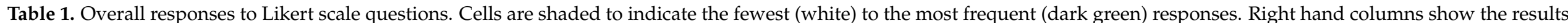

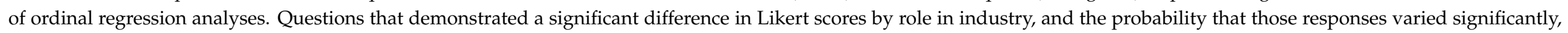
are highlighted in grey and denoted in bold.

\begin{tabular}{|c|c|c|c|c|c|c|c|c|c|c|c|c|}
\hline \multirow[t]{2}{*}{ Question } & \multicolumn{5}{|c|}{ Likert Responses } & \multicolumn{5}{|c|}{ Hypothesis Test } & \multicolumn{2}{|c|}{$95 \%$ Confidence Interval } \\
\hline & 1 & 2 & 3 & 4 & 5 & $\mathbf{n}$ & Wald Chi-Square & df & $p$ Value & Odds Ratio & Lower & Upper \\
\hline 1. Working with livestock is enjoyable to me & $68 \%$ & $27 \%$ & $3 \%$ & $0 \%$ & $1 \%$ & 263 & 3.555 & 1 & 0.059 & 1.117 & 0.996 & 1.254 \\
\hline 2. Livestock do not form relationships with humans & $4 \%$ & $17 \%$ & $8 \%$ & $40 \%$ & $31 \%$ & 258 & 0.578 & 1 & 0.447 & 1.037 & 0.944 & 1.141 \\
\hline 3. If I see an animal suffer, I think about it for a long time & $38 \%$ & $36 \%$ & $12 \%$ & $11 \%$ & $3 \%$ & 257 & 8.527 & 1 & 0.003 & 0.867 & 0.788 & 0.954 \\
\hline 4. Livestock are stupid & $8 \%$ & $5 \%$ & $6 \%$ & $47 \%$ & $34 \%$ & 258 & 4.212 & 1 & 0.040 & 0.903 & 0.819 & 0.995 \\
\hline 5. Livestock are uncontrollable & $2 \%$ & $5 \%$ & $3 \%$ & $49 \%$ & $41 \%$ & 260 & 0.223 & 1 & 0.637 & 0.976 & 0.883 & 1.079 \\
\hline 6. Livestock have feelings & $56 \%$ & $33 \%$ & $6 \%$ & $3 \%$ & $2 \%$ & 261 & 9.704 & 1 & 0.002 & 0.851 & 0.769 & 0.942 \\
\hline 7. Cattle don't feel pain & $5 \%$ & $3 \%$ & $1 \%$ & $32 \%$ & $59 \%$ & 259 & 0.159 & 1 & 0.690 & 0.979 & 0.885 & 1.085 \\
\hline 8. I can see if livestock are stressed & $44 \%$ & $48 \%$ & $7 \%$ & $0 \%$ & $0 \%$ & 260 & 0.235 & 1 & 0.628 & 1.025 & 0.927 & 1.134 \\
\hline 9. Hitting cattle helps when moving them * & $1 \%$ & $2 \%$ & $30 \%$ & $37 \%$ & $31 \%$ & 259 & 2.509 & 1 & 0.113 & 1.079 & 0.982 & 1.186 \\
\hline 10. It is acceptable to pull a sheep by a leg to move them * & $2 \%$ & $1 \%$ & $15 \%$ & $26 \%$ & $57 \%$ & 255 & 0.000 & 1 & 0.998 & 1.000 & 0.902 & 1.108 \\
\hline 11. Sheep don't feel pain & $1 \%$ & $1 \%$ & $2 \%$ & $35 \%$ & $61 \%$ & 259 & 2.058 & 1 & 0.151 & 1.081 & 0.972 & 1.203 \\
\hline $\begin{array}{l}\text { 13. When moving livestock, it is better to remain calm } \\
\text { than shout in a loud voice }\end{array}$ & $56 \%$ & $33 \%$ & $4 \%$ & $4 \%$ & $3 \%$ & 262 & 0.983 & 1 & 0.321 & 0.950 & 0.859 & 1.051 \\
\hline $\begin{array}{l}\text { 14. It is important to move livestock slowly } \\
\text { ing }\end{array}$ & $45 \%$ & $46 \%$ & $6 \%$ & $2 \%$ & $1 \%$ & 259 & 0.150 & 1 & 0.699 & 0.980 & 0.887 & 1.084 \\
\hline 15. I am not upset when I see livestock in pain & $2 \%$ & $5 \%$ & $5 \%$ & $42 \%$ & $46 \%$ & 262 & 3.863 & 1 & 0.049 & 1.107 & 1.000 & 1.226 \\
\hline $\begin{array}{l}\text { 16. It is important for livestock to be able to lie down } \\
\text { to rest }\end{array}$ & $60 \%$ & $34 \%$ & $4 \%$ & $2 \%$ & $0 \%$ & 260 & 0.197 & 1 & 0.657 & 0.977 & 0.882 & 1.083 \\
\hline 17. When I see an animal being bullied, I feel sorry for it & $52 \%$ & $40 \%$ & $6 \%$ & $1 \%$ & $2 \%$ & 261 & 14.025 & 1 & 0.000 & 0.822 & 0.741 & 0.911 \\
\hline $\begin{array}{l}\text { 18. Euthanasia is sometimes necessary in cases of injured } \\
\text { or sick livestock }\end{array}$ & $46 \%$ & $34 \%$ & $10 \%$ & $9 \%$ & $1 \%$ & 257 & 3.079 & 1 & 0.079 & 1.092 & 0.990 & 1.205 \\
\hline $\begin{array}{l}\text { 19. People in my workplace work hard to care for } \\
\text { the livestock }\end{array}$ & $68 \%$ & $29 \%$ & $2 \%$ & $1 \%$ & $1 \%$ & 261 & 1.659 & 1 & 0.198 & 0.930 & 0.833 & 1.038 \\
\hline $\begin{array}{l}\text { 20. The welfare of animals is satisfactory in } \\
\text { my workplace }\end{array}$ & $58 \%$ & $38 \%$ & $3 \%$ & $1 \%$ & $1 \%$ & 261 & 1.016 & 1 & 0.314 & 0.948 & 0.856 & 1.051 \\
\hline $\begin{array}{l}\text { 22. Sometimes, I cannot do anything to improve poor } \\
\text { animal welfare in my workplace }\end{array}$ & $3 \%$ & $18 \%$ & $12 \%$ & $36 \%$ & $30 \%$ & 249 & 1.271 & 1 & 0.260 & 0.944 & 0.853 & 1.044 \\
\hline $\begin{array}{l}\text { 23. In the past, I have tried to make improvements to the } \\
\text { welfare of animals in my work place }\end{array}$ & $41 \%$ & $43 \%$ & $10 \%$ & $5 \%$ & $1 \%$ & 251 & 0.624 & 1 & 0.429 & 1.042 & 0.940 & 1.155 \\
\hline 24. I feel confident working with livestock * & $69 \%$ & $19 \%$ & $8 \%$ & $2 \%$ & $2 \%$ & 259 & 1.022 & 1 & 0.312 & 1.060 & 0.947 & 1.187 \\
\hline
\end{tabular}

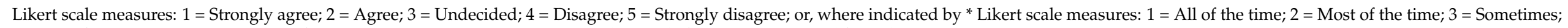
$4=$ Not often; $5=$ Never, $n=$ number of responses. (Survey questions not in a Likert scale format were omitted from these analyses). 
Permission to distribute surveys and flyers was sought from export company directors, ship captains, or feedlot managers. Data were collected from participants working at three major exporting companies, on ten ships, six feedlots (four Australian and two foreign feedlots), and an industry (LiveCorp) stockpersons' accreditation course in Fremantle, Western Australia. Respondents included exporters and their agents, stock handlers working in feedlots, on ships and at the wharf, road transport drivers, veterinarians, importers and their agents, producers, suppliers, and those in administrative roles. One export company declined the invitation to participate in the survey.

To determine the minimum required sample size, we generously estimated a sample population of 8000 industry workers whose roles involved livestock welfare within the Australian live export industry supply chain. We then applied a confidence interval of 95\% and a margin of error at less than $10 \%(7 \%)$ and calculated192 participants as the minimum number of survey participants required [31]. Not all respondents answered all questions; however, the minimum number of participants was easily met in each case.

\subsection{Statistical Analysis}

Survey responses were combined into an Excel spreadsheet [32] and checked for robustness with question comprehension and inconsistent answers. Descriptive statistics were generated by numerically coding data responses. Responses for each Likert scale score were reported for all questions (Table 1). The percentages reported in the text were calculated by pooling Likert scale answers in agreeance (Scores 1 and 2), reporting the percentage of undecided respondents, or by calculating the percentage of responses disagreeing with each question (Scores 3 and 4).

'Industry role' described the sector within the supply chain where a worker was engaged. Participants were divided into ten categories according to their industry roles and grouped as: exporters or exporter's representatives; Australian feedlot workers; truck drivers or stevedores in Australia; shipboard stockpersons; ship's crew; ship's officers; workers 'in-market' (at feedlots or companies in countries receiving Australian livestock); veterinarians; those who did not disclose their role; and 'other', which were those that reported positions that did not fit into the categories provided (such as administrative roles, suppliers to the industry, or producers). Many participants gave multiple responses to the question What is your role in industry? $(n=308)$; therefore, responses were ordered so that their role was listed under the category with the fewest survey respondents. Statistical analysis via ordinal regression using SPSS, version 24 [33] was undertaken on Likert scale responses (Parts 2 and 3) with industry role entered as a categorical covariate and responses entered as the dependent variable.

Responses to open-ended questions were organized into categories based on themes identified within the comments. Responses regarding the welfare improvements identified were categorized as provision of feed and water; provision of good housing; improved livestock management practices; training and education; ensuring livestock health; improving company policies; and preparation of livestock for transport. Suggestions for improving the welfare of exported animals were grouped as adequate provision of feed and water; improvements in housing; facilities and infrastructure; and better preparation and selection of livestock. These responses were analyzed by comparing the number of comments identified under each category.

\section{Results}

\subsection{Demographics of Respondents}

Of the 265 responses received, many were completed in English (49\%), with the remainder in Filipino (25\%), Bangla (20\%), Vietnamese (4\%), and Bahasa (2\%) (Figure 1a). The predominant nationalities were Filipino (29.8\%), Australian and New Zealander (32.8\%) and Bangladeshi (20.0\%) (Figure 1b). Filipino respondents either worked on ships (comprising $62.4 \%$ of the crew demographic and $18.5 \%$ of the ship's officers) or did not disclose their industry role. Australian and New Zealand participants worked in all industry roles 
except for the ship's crew or officers. The Bangladeshi workers contributed to $34.6 \%$ of the ship's crew and $51.9 \%$ of the ship's officers. The remaining Bangladeshi participants $(13.5 \%)$ worked in-market. The Filipino respondents predominantly identified as Christian (97.5\%) and Bangladeshi respondents as Muslim (98.1\%). Australian respondents were predominantly Christian $(44.0 \%)$ or atheist $(25.3 \%)$, while $28.0 \%$ choose not to respond to this question (Figure 1c).

Participants were mostly male $(86.8 \%)$; exporters or their representatives and the category 'other roles' had the highest representation of women (33.3\% of 36 respondents, and $50 \%$ of 10 respondents, respectively) (Figure 1d). There was a relatively even distribution of ages, from below 30 years of age (28.3\%), 30-39 years (24.2\%), 40-49 years $(20.4 \%)$ and more than 50 years $(20.0 \%)$ (Figure 1 e).

Roles identified were exporters or their representative (13.6\%); Australian pre-export feedlot workers $(4.5 \%)$; truck drivers or stevedores $(4.5 \%)$; ship's crew $(38.1 \%)$; officers $(10.2 \%)$ and shipboard stockpersons on-board livestock vessels $(6.8 \%)$. Other roles were in-market workers at feedlots or companies that received Australian livestock (7.9\%), veterinarians working across all areas of the supply chain $(3.0 \%)$, while $3.8 \%$ of respondents worked in other roles such as administration or finance. A proportion of respondents $(7.6 \%)$ chose not to disclose their role in industry.

Most respondents had either completed high school (24.2\%) or had higher education in the form of a trade certificate or tertiary degree (61.9\%) (Figure 1f). Despite high levels of further education or training, very few respondents declared that they had received any formal training with livestock (22.3\%) (Figure 1g). Besides veterinarians and shipboard stockpersons (whose roles require formal training), Australian feedlot workers were most likely to report formal training $(66.6 \%)$. In comparison, $10.9 \%$ of ship's crew and none of the ship's officers reported having any formal training with livestock. This question had the highest non-response rate for the survey $(n=125)$.

Although many workers did not have formal training with livestock, they had extensive experience with farm animals, either in Australia or other parts of the world. Of the $67.2 \%$ of respondents who were not Australian or New Zealander by nationality $(n=178)$, $53.9 \%$ reported that they had experience working with farm animals not from Australia (Figure 1h).

\subsection{Overall Attitudes to Welfare}

When answering questions on beliefs about animal welfare, participants in all sectors showed a high level of agreement when responding to the statements working with livestock is enjoyable to me (95.8\%), the welfare of livestock in my workplace is important to me (98.9\%), and livestock should be treated with respect $(97.7 \%)$. When considering sentience, only $5.0 \%$ of participants disagreed with the statement livestock have feelings, and $21.3 \%$ of participants agreed with the statement livestock do not form relationships with humans. Only $0.8 \%$ disagreed with the statement I can see if livestock are stressed. Participants' understanding of pain perception in livestock was reflected by only $8.1 \%$ agreeing with the statement cattle don't feel pain, and only $2.3 \%$ agreeing with the statement sheep don't feel pain. When considering euthanasia, $80.2 \%$ of participants agreed that euthanasia was sometimes necessary in cases of sick or injured livestock, while $10.1 \%$ were undecided, and $9.7 \%$ disagreed.

Statements concerning knowledge around animal handling and management showed most participants demonstrated a good understanding of the needs of animals, and replies were consistent with favorable livestock handling practices. Attitudes toward acceptable animal handling were reflected by responses to the statements: hitting cattle helps when moving them (only $2.3 \%$ agreed); and it is acceptable to pull a sheep by a leg to move them (2.4\% agreed) (Table 1). Most (90.3\%) participants agreed that it is important to move livestock slowly, $93.5 \%$ agreed that it is important for livestock to be able to lie down to rest, and $89.3 \%$ agreed that when moving livestock, it is better to remain calm than shout in a loud voice (Table 1). 


\subsection{Animal Welfare within the Workplace}

When asked if the welfare of animals is satisfactory in my workplace, $95.8 \%$ of respondents agreed, $2.7 \%$ were undecided, and $1.5 \%$ disagreed (Table 1). Two-thirds of respondents (164 respondents or $61.9 \%$ ) provided 256 ideas and suggestions when asked to outline ways to improve the welfare of exported animals. Workers gave responses regarding adequate provision of feed and water (59 comments), improvements in housing, facilities, and infrastructure (51 comments). Better preparation and selection of livestock was suggested in 39 comments. Examples of responses include: "Increase feed onboard, especially chaff", "Improvement or abolishment of older ships," and "Cattle should be brought to the vessel in good condition. Mostly cattle that are brought onboard are very frightened of human beings." Five respondents stated that animal welfare in the livestock export industry is currently acceptable and did not have any suggestion for further improvement.

The respondents' perception of co-workers and their consideration of acceptable workplace practices showed that $96.9 \%$ agreed that the people in [their] workplace work hard to care for the livestock. Assessment of perceived behavioral control and the ability to act in accordance with the beliefs highlighted above was reflected by agreement with the statement I feel confident working with livestock (88.4\% agreed), and disagreement with the statement livestock are uncontrollable ( $90.0 \%$ disagreed). More respondents had positive rather than negative views toward their ability to effect change, with $66.7 \%$ disagreeing with the statement: sometimes, I cannot do anything to improve poor animal welfare in my workplace (Table 1).

Participants agreed (84.5\%) that they had tried to improve the welfare of animals in their workplace in the past, while $10.0 \%$ were undecided (Table 1). Comments were given by 168 participants (63.4\%) in response to the question: Can you give an example of how you have improved animal welfare in your workplace? Responses included 251 relevant examples of animal welfare improvements they had made in the past. Comments concerning the provision of feed and water were the most frequent (69), comments regarding provision of good housing or good livestock management practices were frequently given ( 54 comments on each), as were those on training and education (37). Further comments were made on ensuring livestock health, improving company policies, and preparation of livestock for transport. Examples include: "Work place training to better my skills in livestock handling" and "We make sure we give them enough food and water regularly and clean their pens."

\subsection{Understanding of Welfare by Role in Industry}

Five of the 24 Likert scale questions showed a significant difference between respondents' workplace roles (Table 1). Of these, three were related to feeling empathy toward livestock in cases of poor welfare. Responses to the statement: If I see an animal suffer, I think about it for a long time, showed that although $50.0 \%$ of Australian feedlot workers agreed, unlike all other groups, no feedlot workers strongly agreed with the statement. Australian feedlot workers were also more likely to strongly disagree (33.3\%) with this statement when compared to all other workplace roles (Figure 2a).

The majority of participants in all sectors disagreed with the statement: I am not upset when I see livestock in pain. However, participants who did not disclose their industry role showed more variability in their responses than other groups, with a wide range of scores ( $25 \%$ in agreement, $10 \%$ undecided, and $65.0 \%$ disagreed) (Figure $2 b$ ).

Few respondents from any group disagreed with the statement: When I see an animal being bullied, I feel sorry for it; however, there was a difference in the level of agreement between those in different industry roles. The majority of ship's crew, ship's officers, in-market workers, veterinarians, and those in 'other' positions strongly agreed with the statement. In contrast, truck drivers and stevedores in Australia, shipboard stockpersons, Australian feedlot workers, and the undisclosed group were more likely to select agree or undecided in response to the statement. Exporters and exporters' representatives were evenly divided between agreed (47.2\%) or strongly agree (47.2\%) (Figure 2c). 
a) Q3. If I see an animal suffer, I think about it for a long time $(n=257)$

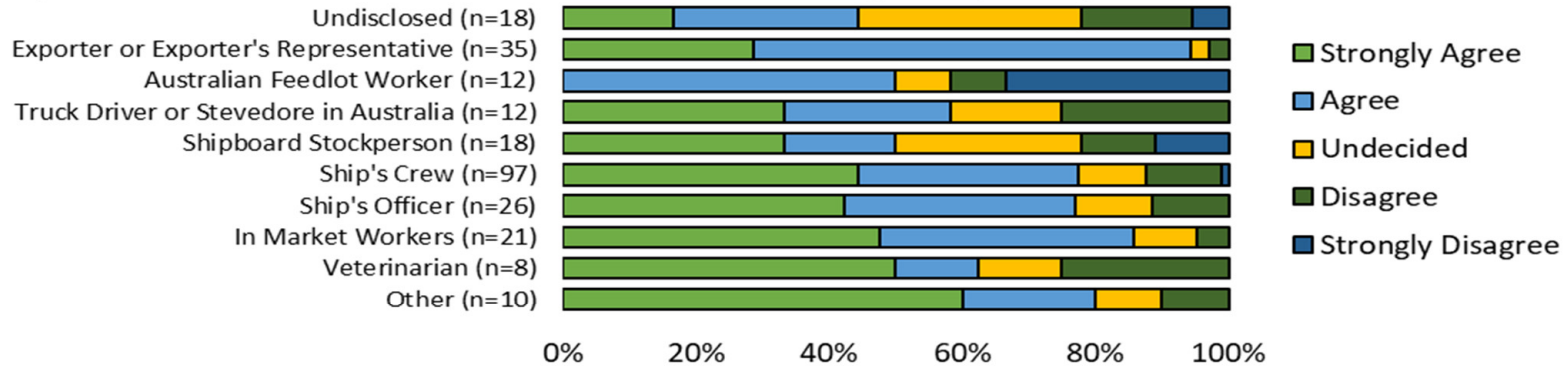

b) Q15. I am not upset when I see livestock in pain $(n=262)$

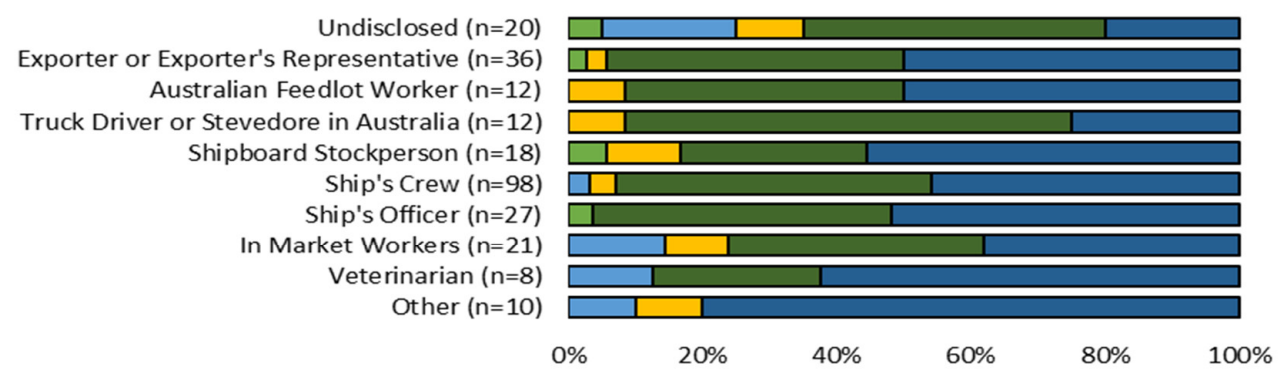

c) Q17. When I see an animal being bullied, I feel sorry for it $(n=261)$

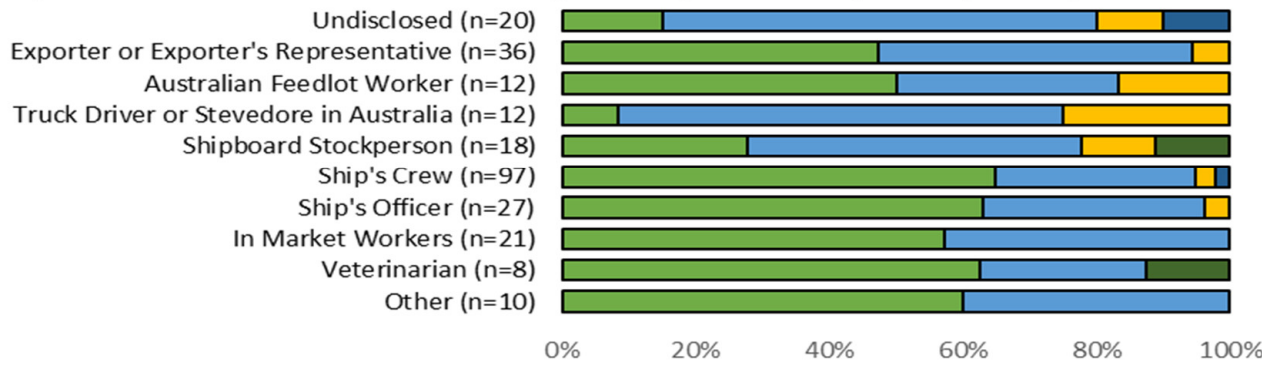

d) Q4. Livestock are stupid $(n=258)$

Undisclosed $(\mathrm{n}=20)$

Exporter or Exporter's Representative $(n=36)$

Australian Feedlot Worker $(n=12)$

Truck Driver or Stevedore in Australia $(n=12)$

Shipboard Stockperson $(n=18)$

Ship's Crew ( $\mathrm{n}=96)$

Ship's Officer $(n=26)$

In Market Workers $(n=20)$

Veterinarian $(n=8)$

Other $(n=10)$

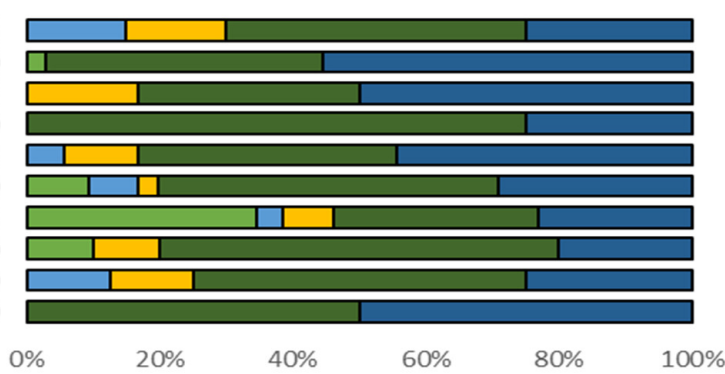

e) Q6. Livestock have feelings $(n=261)$

Undisclosed $(n=20)$

Exporter or Exporter's Representative $(n=36)$ Australian Feedlot Worker $(n=12)$ Truck Driver or Stevedore in Australia $(n=12)$

Shipboard Stockperson $(n=18)$ Ship's Crew $(n=98)$ Ship's Officer $(n=26)$ In Market Workers $(n=21)$ Veterinarian $(n=8)$ Other $(n=10)$

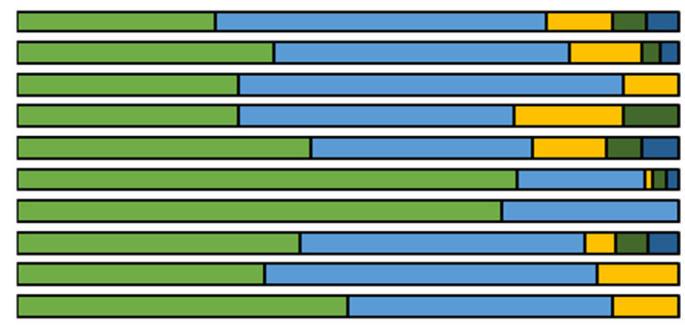

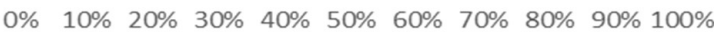

Figure 2. (a-e) Survey responses for questions that differed significantly by role in industry.

The two remaining questions that showed a significant difference by workplace were related to beliefs about animal sentience. The majority of respondents in all groups disagreed with the statement: livestock are stupid. However, ship's officers had a greater percent- 
age of answers in agreeance (33.3\% strongly agreed) than any other group (Figure $2 \mathrm{~d}$ ). Despite this finding, ship's officers, along with ship's crew, were more likely than other groups to strongly agree that livestock have feelings (74.4\% and 73.2\%, respectively) (Figure 2e). Furthermore, ship's officers were the only group to agree with the statement unanimously.

Participants that disagreed with the statement euthanasia is sometimes necessary in cases of injured or sick livestock were ship's crew (20 respondents), in-market workers (four respondents), or a ship's officer (one respondent) (Table 1). However, as the majority of respondents in these groups agreed with the statement, there was no significant difference detected by industry role.

\section{Discussion}

The principal aim of the study was addressed by responses demonstrating that workers within the livestock export industry had a good understanding of welfare concepts and animal sentience and held positive attitudes toward the animals under their care. Participants also felt positive about their workplace and provided ways to improve welfare outcomes; there were no sectors with consistently convergent in their beliefs or attitudes, addressing our second and third aims, respectively.

Livestock export workers' views on animal sentience were comparable to the $1521 \mathrm{mem}$ bers of the Australian public surveyed on farm animal welfare by Futureye [17]. The majority of the public agreed that animals have the capacity to experience stress (86\%), have desires and wants (73\%), and have the capacity to experience joy and pleasure (81\%). Similarly, the livestock export workers in our survey agreed that they could see if livestock were stressed (92.7\%) and that livestock had feelings (89.3\%). Futureye [17] found that $87 \%$ of the Australian public believed that animals were aware of bodily sensations such as pain, heat, cold, or hunger. Similarly, the livestock export workers in our survey disagreed with the statements that cattle do not feel pain (91.1\%), or sheep do not feel pain $(96.1 \%)$, demonstrating their understanding of sentience. These comparable responses suggest that the views of livestock export industry workers captured in our study align with those of the Australian public.

Previous studies on human-animal relationships demonstrate that behavioral intent precedes displayed human behavior and is influenced by (1) having a positive attitude toward a behavior; (2) feeling that the behavior is a favorable social norm; and (3) having perceived behavioral control [21]. Responses to questions examining the participants' attitudes and beliefs toward welfare concepts generally indicated positive attitudes and values, suggesting industry workers would endeavor to treat animals well. Questions assessing favorable social norms within the workplace highlighted that workers did not widely accept poor handling practices and commonly recognized that people worked hard to care for livestock. Workers also demonstrated that they had perceived behavioral control as they typically felt confident in their roles and expressed that they can take action to provide desirable welfare outcomes for the animals under their care. These findings show that a substantial majority of surveyed livestock export industry workers displayed positive intent toward taking measures to improve animal welfare.

It is not possible to verify how people will act in their workplaces based on survey data, and intention alone does not confirm how people will behave in a specific context. Sinclair et al. [24] surveyed stakeholders' attitudes toward livestock transport and slaughter in Southeast and East Asia. Most participants in their study expressed positive attitudes toward improving animal welfare by indicating that welfare was important to them; however, fewer respondents agreed that they intended to make improvements to the welfare of animals. Similarly, Verrinder and Phillips [34] reported that although the veterinary students they surveyed felt strongly motivated to act in the interest of animals, many felt they had taken little affirmative action to improve animal welfare. The majority of workers completing this survey indicated that welfare was important to them, and most reported having improved animal welfare in the past. When subsequently asked to give specific examples of having done so, most participants could provide one or more 
responses. These examples were focused on key welfare principles such as provision of resources "feeding them every day"; care for the environment "ensure ventilation 24 "; good stockmanship "low stress animal handling"; and continued training and education of workers "teaching new employees how to handle stock and identify stressed animals". This sample of livestock export industry workers showed positive behavioral intent toward affirmative action, combined with evidence of past behavior focused on prioritizing animal welfare improvement in the workplace.

Respondents predominantly enjoyed working with livestock and felt positive about welfare within their workplace. These findings complement studies of workers in other production animal sectors that found people tended to enjoy working with livestock on a daily basis [5]. Furthermore, a 2021 industry survey on live exports indicated that the majority of workers showed a high level of acceptance of the industry and felt the industry listened to and respected community opinions [18]. Although the industry survey did not directly canvass worker's views on animal welfare, this is a particular point of issue for the live export, and it can be assumed that their views on animal welfare would have strongly influenced responses on industry acceptability. The majority of respondents to our survey provided suggestions for ongoing improvements to animal welfare in their workplace, indicating that workers recognized welfare concerns and are a valuable source of information to enhance animal welfare outcomes for the industry.

It is well recognized that those who work in animal production tend to view welfare within their workplace more favorably than members of the public [35]. European studies comparing farmers' views with those of the public found that farmers tend to assess welfare based on optimal health and access to resources within their management systems. However, the public tended to judge welfare outcomes based on optimal health, access to resources, and the ability for animals to engage in natural behavior $[35,36]$. The discordance between livestock export industry workers' and the general publics' views on the welfare of exported livestock is likely based on their interpretation of the importance of different components of welfare. Furthermore, industry workers base their perceptions on their day-to-day experiences of routine trade practices rather than information from media articles and advocacy campaigns centering on extreme events of poor welfare [1,3].

The effect of role along the Australian export supply chain was investigated, noting that diverse demographic groups represented each role. Gender has previously been reported as an influencing factor when assessing attitudes to animal welfare [25-27]. The gender of survey respondents reflected the male-dominated industry with shipboard workers, truck drivers, and stevedores, and Australian feedlot workers being predominantly male; however, other roles were more gender diverse. Despite the different gender demographics between roles, no differences in survey responses were found. Roles varied in religiosity, with participants from Australia or New Zealand less likely to hold religious beliefs than those of other nationalities who were predominantly Christian or Islamic. Religion has been reported as an influencing factor for beliefs regarding transport and slaughter of livestock [24,25] but did not affect responses in our study. Formal training in livestock handling has been recognized to influence attitudes toward animal welfare $[5,26,27]$; however, despite the discrepancy in formal training reported by workers, this had limited influence on our results.

Despite the overall convergence of beliefs and attitudes across industry roles, there was some subtle variance. When considering animal sentience, all ship's officers and most ship's crew $(95.0 \%)$ agreed or strongly agreed that livestock have feelings; however, ship's officers were more likely than others to agree that livestock are stupid. These results may reflect ship officer's interactions with livestock: although they frequently make decisions that impact animal welfare, officers often have limited experience directly handling livestock and observing the nuances of livestock behavior [37]. Notably, three of the five questions showing a significant effect of industry role were statements requiring self-reflection. These questions required an awareness of the animal perspective as well as the respondent's own emotional reaction to a situation. Although workers in Australian feedlots, 
truck drivers, and stevedores in Australia, and those in undisclosed roles all expressed agreement with questions supporting animal sentience, when asked if they were personally affected by poor animal welfare, these respondents were less likely to agree. These findings may indicate differences in the way respondents perceive their own emotions rather than the animal welfare concepts presented in the question. Regardless of their role in the supply chain, respondents generally demonstrated a good understanding of animal welfare and indicated that welfare was an important concern to them. It is notable that some respondents did not agree that euthanasia was sometimes necessary in cases of injured or sick livestock. As this question was primarily answered favorably, there was no significant difference identified by industry role; however, all those who held these beliefs were workers on ships or in destination markets. A previous survey of Southeast and East Asian students recognized that respondents from a rural residence, and those with more farm animal experience, were less accepting of killing seriously injured or ill animals [25]. Our findings may be related to the high proportion of shipboard and in-market workers who have worked with farm animals that are not from Australia and the relatively high importance and economic value of individual animals to farmers in developing nations [38].

Strong opinions and potential misconceptions exist regarding workers in the live export industry. A survey of the Australian public found they placed higher levels of trust in veterinarians than other stakeholders directly employed in the live export context [16]; however, it was not specifically stated against which other industry stakeholders they were compared. Other reports have highlighted the public's particular concerns regarding workers involved in transporting animals by sea and those who handle animals in countries receiving Australian livestock $[3,13]$. Our study countered these sentiments by showing that industry workers' attitudes toward animal welfare generally did not vary according to their role in the supply chain. The public's perceptions perhaps reflect systemic industry issues prior to the introduction of the Export Supply Chain Assurance System (ESCAS) in 2011. Despite ESCAS improvements, the media's framing of events involving poor welfare in destination countries typically aims to promote moral shock rather than providing objective information regarding animal welfare issues within the supply chain [1,4]. Furthermore, incidents occurring outside Australia are rarely put in perspective against production animal welfare issues that exist domestically. Changing negative perceptions of industry workers and viewing them as a competent resource for understanding and implementing welfare regulations will help drive ongoing industry improvement [15].

This study suggests that participants were highly likely to display behavior that led to or optimized welfare outcomes when it was feasible to do so. The ability of stock handlers to deliver good welfare outcomes depends on actual behavioral control and may be hampered by factors beyond the individual's control [30]. To effect positive interactions, it is necessary to provide people with resources and opportunities to perform the desired behavior and make ongoing improvements to animal welfare $[5,22]$. Findings suggest that when welfare outcomes do not meet societal expectations, contributing factors are likely to be beyond the control of those directly handling livestock. Industry issues such as availability of resources, inappropriate infrastructure, adverse environmental conditions, lack of training, or a combination of multiple factors [39] are more pertinent causes of undesirable welfare outcomes rather than worker complacency or deliberate mishandling of livestock.

Many people working in the livestock export supply chain outside Australia enter the industry with limited experience handling Australian livestock and develop skills experientially on the job rather than by formal training. Receiving training in effective stock handling practices can significantly improve human-animal interactions $[5,15]$. The implementation of ESCAS has improved handling and infrastructure in foreign facilities but does apply to domestic facilities or shipboard workers. Although very few participants who did not demonstrate a proficient understanding of animal welfare concepts, the low level of formal training reported identifies this as an area where improvements can be achieved, both domestically and internationally. Industry investment in staff training, maximizing 
worker retention, and creating a positive workplace environment can significantly improve animal welfare outcomes [15].

Most participants completed the surveys in the workplace at times of high activity (for example, during vessel loading or receival of livestock at a feedlot). However, it is known that emotional valence at the time of decision making can influence behavior $[5,30]$ and survey context does not account for a participant's affective state, or the influence of external factors [6] when handling livestock. Hence, directly recording observed behavior in the workplace can further improve our understanding of stock handlers' interactions with animals. Surveying a control group of stock handlers not associated with the livestock export industry, or members of the general public, would add value to this study, as would sourcing information from more pre-export facilities and destination markets. The exclusion of workers from one exporting company reduces the scope of responses to reflect all industry workers accurately.

\section{Conclusions}

Respondents demonstrated a good understanding of animal welfare and displayed positive attitudes and empathy toward working with livestock. People from all sectors of the supply chain showed positive intent toward improving animal outcomes and indicated that taking affirmative action on animal welfare was the social norm in their workplace. Surveyed workers reported a high level of perceived behavioral control around efforts to improve welfare outcomes. These fundamental elements indicate the likelihood of workers displaying behavior that positively influences animal welfare. There were few differences in attitudes, beliefs, or actions between industry roles, indicating that, where feasible, livestock export industry workers will behave in a way that optimizes animal outcomes regardless of their role in the supply chain. Many workers provided descriptions of welfare improvements they had undertaken in the past and suggestions for future improvements. These findings are important for guiding future animal welfare policy and developing communication strategies to deal with the public's perception of workers within the industry.

Author Contributions: Conceptualization, T.C.; Methodology, formal analysis and investigation, R.S.W., E.J.D.-C., L.R.K., P.A.F., T.C.; Writing—original draft preparation, R.S.W.; Writing-review and editing, R.S.W., E.J.D.-C., L.R.K., P.A.F., T.C.; Supervision, T.C.; Funding acquisition, T.C. All authors have read and agreed to the published version of the manuscript.

Funding: Funding was provided by Murdoch University and the Australian Veterinary Association Animal Welfare Trust.

Institutional Review Board Statement: This study was conducted according to the guidelines of the National Statement on Ethical Conduct in Human Research and the Declaration of Helsinki, and is approved by the Murdoch University Human Research Ethics Committee (2018/022).

Data Availability Statement: Data contains personal and industry sensitive information and public sharing of data has not been granted by survey participants. Therefore, limited data is available only upon request due to ethical restrictions.

Acknowledgments: The authors acknowledge the facilitation of access to industry workers by Meat and Livestock Australia Pty Ltd., and LiveCorp; North Sydney, Australia. We thank those who helped to distribute the survey, and the survey respondents for their participation in this study.

Conflicts of Interest: R.S.W. undertakes employment as an Australian Government Accredited Veterinarian; Co-author T.C. undertakes occasional advisory roles for DAWE; all authors excluding L.R.K. have received funding from Meat and Livestock Australia on alternate research grants. The funders had no role in the design of the study; in the collection, analyses, or interpretation of data; in the writing of the manuscript, or in the decision to publish the results.

\section{References}

1. Buddle, E.A.; Bray, H.J. How Farm Animal Welfare Issues are Framed in the Australian Media. J. Agric. Environ. Ethics 2019, 32, 357-376. [CrossRef]

2. Coleman, G. Public animal welfare discussions and outlooks in Australia. Anim. Front. 2018, 8, 14-19. [CrossRef] 
3. Hampton, J.O.; Jones, B.; McGreevy, P.D. Social License and Animal Welfare: Developments from the Past Decade in Australia. Animals 2020, 10, 2237. [CrossRef] [PubMed]

4. Munro, L. The Live Animal Export Controversy in Australia: A Moral Crusade Made for the Mass Media. Soc. Mov. Stud. 2015, 14, 214-229. [CrossRef]

5. Hemsworth, P.H.; Coleman, G.J. Human-Livestock Interactions: The Stockperson and the Productivity and Welfare of Intensively Farmed Animals, 2nd ed.; CABI: Wallingford, UK, 2011; ISBN 13: 9781845936730.

6. Burnard, C.L.; Pitchford, W.S.; Edwards, J.H.; Hazel, S.J. Facilities, breed and experience affect ease of sheep handling: The livestock transporter's perspective. Animal 2015, 9, 1379-1385. [CrossRef]

7. Mellor, D.J.; Beausoleil, N.J.; Littlewood, K.E.; McLean, A.N.; McGreevy, P.D.; Jones, B.; Wilkins, C. The 2020 Five Domains Model.: Including Human-Animal Interactions in Assessments of Animal Welfare. Animals 2020, 10, 1870. [CrossRef] [PubMed]

8. Fleming, P.A.; Wickham, S.L.; Barnes, A.L.; Miller, D.W.; Collins, T. Varying Opinions about Animal Welfare in the Australian Live Export Industry: A Survey. Animals 2020, 10, 1864. [CrossRef]

9. Fleming, P.A.; Wickham, S.L.; Dunston-Clarke, E.J.; Willis, R.S.; Barnes, A.L.; Miller, D.W.; Collins, T. Review of livestock welfare indicators relevant for the Australian live export industry. Animals 2020, 10, 1236. [CrossRef]

10. Doyle, R.E.; Coleman, G.J.; McGill, D.M.; Reed, M.; Ramdani, W.; Hemsworth, P.H. Investigating the welfare, management and human-animal interactions of cattle in four Indonesian abattoirs. Anim. Welf. 2016, 25, 191-197. [CrossRef]

11. Australian Broadcasting Commission. Four Corners. In A Bloody Business; ABC: Sydney, Australia, 2011.

12. Department of Agriculture Water and the Environment. Exporter Supply Chain Assurance System (ESCAS). 2020. Available online: https:/ / www.agriculture.gov.au/export/controlled-goods/live-animals/livestock/information-exporters-industry/escas (accessed on 18 February 2021).

13. Buddle, E.A.; Bray, H.J.; Ankeny, R.A. “I Feel Sorry for Them”: Australian Meat Consumers' Perceptions about Sheep and Beef Cattle Transportation. Animals 2018, 8, 171. [CrossRef]

14. Sinclair, M.; Derkley, T.; Fryer, C.; Phillips, C.J. Australian public opinions regarding the live export trade before and after an animal welfare media exposé. Animals 2018, 8, 106. [CrossRef] [PubMed]

15. Daigle, C.L.; Ridge, E.E. Investing in stockpeople is an investment in animal welfare and agricultural sustainability. Anim. Front. 2018, 8, 53-59. [CrossRef] [PubMed]

16. Moffat, K. Live Exports and the Australian Community: A National Survey; Voconiq: Bowen Hills, Australia, 2020; Available online: https:/ / voconiq.com/livecorp/ (accessed on 28 November 2020).

17. Futureye. Australia's Shifting Mindest on Farm. Animal Welfare; Futureye Pty Ltd.: Windsor, VIC, Australia, 2018. Available online: https:/ / www.agriculture.gov.au/animal/welfare/animal-welfare-in-australia\#research-and-development (accessed on 1 December 2020).

18. Livecorp and Voconiq. Industry Survey on Livestock Exports; Livecorp: North Sydney, Australia, 2021; Available online: https: / /livecorp.com.au/publication/5h1FnKdhnmjqzkd8eSC9RI (accessed on 4 March 2021).

19. Sinclair, M.; Phillips, C.J. Asian Livestock Industry Leaders' Perceptions of the Importance of, and Solutions for, Animal Welfare Issues. Animals 2019, 9, 319. [CrossRef] [PubMed]

20. Hanna, D.; Sneddon, I.A.; Beattie, V.E. The relationship between the stockperson's personality and attitudes and the productivity of dairy cows. Animal 2009, 3, 737-743. [CrossRef] [PubMed]

21. Munoz, C.A.; Coleman, G.J.; Hemsworth, P.H.; Campbell, A.J.; Doyle, R.E. Positive attitudes, positive outcomes: The relationship between farmer attitudes, management behaviour and sheep welfare. PLoS ONE 2019, 14, e220455. [CrossRef]

22. Ajzen, I. The theory of planned behavior. Organ. Behav. Hum. Decis. Process. 1991, 50, 179-211. [CrossRef]

23. Breuer, K.; Hemsworth, P.H.; Barnett, J.L.; Matthews, L.R.; Coleman, G.J. Behavioural response to humans and the productivity of commercial dairy cows. Appl. Anim. Behav. Sci. 2000, 66, 273-288. [CrossRef]

24. Sinclair, M.; Zito, S.; Idrus, Z.; Yan, W.; van Nhiem, D.; Lampang, P.N.; Phillips, C. Attitudes of stakeholders to animal welfare during slaughter and transport in SE and E Asia. Anim. Welf. 2017, 26, 417-425. [CrossRef]

25. Ling, R.Z.; Zulkifli, I.; Lampang, P.N.; Nhiem, D.V.; Wang, Y.; Phillips, C.J. Attitudes of students from south-east and east Asian countries to slaughter and transport of livestock. Anim. Welf. 2016, 25, 377-387. [CrossRef]

26. Descovich, K.; Li, X.; Sinclair, M.; Wang, Y.; Phillips, C.J. The Effect of Animal Welfare Training on the Knowledge and Attitudes of Abattoir Stakeholders in China. Animals 2019, 9, 989. [CrossRef]

27. Balzani, A.; Hanlon, A. Factors that Influence Farmers' Views on Farm. Animal Welfare: A Semi-Systematic Review and Thematic Analysis. Animals 2020, 10, 1524. [CrossRef] [PubMed]

28. Waiblinger, S.; Menke, C.; Coleman, G. The relationship between attitudes, personal characteristics and behaviour of stockpeople and subsequent behaviour and production of dairy cows. Appl. Anim. Behav. Sci. 2002, 79, 195-219. [CrossRef]

29. Sinclair, M.; Zito, S.; Phillips, C.J. The impact of stakeholders' roles within the livestock industry on their attitudes to livestock welfare in Southeast and East Asia. Animals 2017, 7, 6. [CrossRef]

30. Ajzen, I. The theory of planned behaviour: Reactions and reflections. Psychol. Health 2011, 26, 1113-1127. [CrossRef] [PubMed]

31. AUSVET. Epitools-Epidemiological Calculators. 2021. Available online: https://epitools.ausvet.com.au/samplesize (accessed on 16 May 2020).

32. Microsoft Corporation. Microsoft Excel; Microsoft Corp.: Redmond, WA, USA, 2016.

33. IBM Corporation. IBM SPSS Statistics; IBM Corp.: Armonk, NY, USA, 2016. 
34. Verrinder, J.M.; Phillips, C.J. Identifying veterinary students' capacity for moral behavior concerning animal ethics issues. J. Vet. Med. Educ. 2014, 41, 358-370. [CrossRef] [PubMed]

35. Vanhonacker, F.; Verbeke, W.; Van Poucke, E.; Tuyttens, F.A. Do citizens and farmers interpret the concept of farm animal welfare differently? Livest. Sci. 2008, 116, 126-136. [CrossRef]

36. Te Velde, H.; Aarts, N.; Van Woerkum, C. Dealing with Ambivalence: Farmers' and Consumers' Perceptions of Animal Welfare in Livestock Breeding. J. Agric. Environ. Ethics 2002, 15, 203-219. [CrossRef]

37. Grandin, T.; Shivley, C. How farm animals react and perceive stressful situations such as handling, restraint, and transport. Animals 2015, 5, 1233-1251. [CrossRef]

38. Riethmuller, P. The social impact of livestock: A developing country perspective. Anim. Sci. J. 2003, 74, 245-253. [CrossRef]

39. Collins, T.; Hampton, J.; Barnes, A. Literature Review of Scientific Research Relating to Livestock Exports; Murdoch University: Perth, Australia, 2018. Available online: https:/ / haveyoursay.agriculture.gov.au/33007/documents/91281 (accessed on 25 July 2019 ). 